\title{
EXPERIMENTAL TESTING OF REINFORCED CONCRETE WALLS IN REGIONS OF LOWER SEISMICITY
}

\author{
Scott J. Menegon', John L. Wilson², \\ Nelson T.K. Lam ${ }^{3}$ and Emad F. Gad ${ }^{4}$
}

(Submitted March 2017; Reviewed June 2017; Accepted July 2017)

\begin{abstract}
This paper provides an overview and the results of a recent experimental study testing the lateral cyclic displacement capacity of limited ductile reinforced concrete (RC) walls. The experimental program included one monolithic cast in-situ rectangular wall specimen and one monolithic cast in-situ box-shaped building core specimen. The specimens were tested using the MAST system at Swinburne University of Technology. They were tested under cyclic in-plane unidirectional lateral load with a shear-span ratio of 6.5. The specimens were detailed to best match typical RC construction practices in regions of lower seismicity, e.g. Australia, which generally results in a 'limited ductile' classification to the Australian earthquake loading code. This reinforcement detailing consisted of constant-spaced horizontal and vertical bars on each face of the wall and lap splices of the vertical reinforcement at the base of the wall in the plastic hinge region. The rectangular wall and building core specimens both achieved a relatively good lateral displacement capacity given the limited ductile reinforcement detailing adopted. The lap splice at the base of the specimens resulted in a somewhat different post-yield curvature distribution being developed. Rather than a typical plastic hinge with distributed cracks being developed, a 'two crack' plastic hinge was formed. This consisted of one major crack at the base of the wall and another at the top of the lap splice, with only hairline cracks developing between these two major cracks. The majority of the plastic rotation was concentrated in each of these two major cracks.
\end{abstract}

\section{INTRODUCTION}

In regions of lower seismicity $\mathrm{RC}$ walls are a popular and widely used lateral load resisting element in many different types of buildings. In Australia, for example, the majority of low, mid and high-rise buildings utilise RC walls - of various cross sections and configurations - as the primary lateral load resisting system of the building. This generally consists of individual isolated rectangular walls, a central building core or a combination of both. The buildings typically then have an RC beam and column gravity frame, which can be in the form of a traditional two-way beam and slab system, band beams with one-way slabs or a flat slab system. Quite commonly the RC beams and or slabs in the floor system are post-tensioned elements to increase span sizes and decrease floor thicknesses.

This paper provides an overview and discussion of a recently completed experimental study the authors have undertaken to examine the in-plane lateral displacement behaviour of $\mathrm{RC}$ walls with limited ductile detailing. The test specimens have been designed to best represent current building practices in Australia, as identified by [1], which is typically classified as 'limited ductile' RC construction and included one rectangular wall specimen and one box-shaped building core specimen.

Seismic design of buildings in regions of lower seismicity ideally consists of initially designing the building for gravity, wind and robustness load cases and then performing a check for seismic compliance at a 'collapse prevention' limit state. A major aspect of this testing program is to assess and then develop a tool for predicting the in-plane lateral displacement capacity of limited ductile RC walls associated with a collapse prevention limit state (i.e. the displacement capacity just prior to axial load failure of the wall)

\section{RESEARCH SIGNIFICANCE}

RC walls in Australia are typically constructed using, what would be considered in regions of higher seismicity, poor detailing practices. This detailing most commonly consists of a constant spaced layer of vertical and horizontal reinforcement on each face of the wall, no confinement reinforcement (i.e. ligatures or stirrups) in the end regions of the wall and lap splices of the vertical reinforcement located at the base of the wall in the plastic hinge zone. The detailing is typically performed in accordance with the main body of the Australian standard for concrete structures, AS 3600 [2], which results in a limited ductile RC structure classification to the Australian standard for earthquake actions, AS 1170.4 [3]. This classification allows the designer to adopt a displacement ductility factor of 2.0 and overstrength factor 1.3 , resulting in a force reduction of 2.6 when performing an equivalent static analysis of the structure.

Further, RC walls used in Australian buildings are typically very slender, flexure controlled elements with shear-span ratios greater than four, configured around lifts and emergency exit stairwells to form box-shaped building cores and with low axial loads [1]. The majority of experimental testing programs of RC walls have typically consisted of rectangular walls with either ductile reinforcement detailing or detailing practices not commonly used in Australia, resulting in very limited experiment test data of $\mathrm{RC}$ walls relevant to Australian construction practices available in literature [1]. This experimental testing program was initiated to assess the seismic performance of RC walls matching current construction practices in Australia, such that displacement-based assessment

\footnotetext{
1 Corresponding Author, Swinburne University of Technology, Melbourne, Australia scott@menegon.com.au

2 Professor, Swinburne University of Technology, Melbourne, Australia

3 Professor, University of Melbourne, Melbourne, Australia

4 Professor, Swinburne University of Technology, Melbourne, Australia
} 
tools can be developed for determining seismic compliance of RC wall buildings in Australia.

\section{EXPERIMENTAL WORK IN LITERATURE}

A comprehensive review of previous experimental testing of $\mathrm{RC}$ walls in literature was performed prior to undertaking this experimental testing program [1]. The authors identified 81 studies where a total of 501 walls were tested. Approximately two-thirds of these tests were rectangular walls and the remaining one-third being non-rectangular wall cross sections. The majority of these tests consisted of walls with ductile wall detailing, i.e. they had confinement reinforcement at the end regions of the walls, with only a minor number of studies looking at walls which would be consistent with limited ductile construction practices in Australian.

In this review it was identified that the following studies had test specimens with similar detailing practices to that which is seen in Australia: Lestuzzi and Bachmann [4] performed shake table test on six rectangular wall specimens, four with ductile and two with limited ductile detailing; Dazio, Beyer and Bachmann [5] performed quasi-static cyclic tests on six rectangular wall specimens, five with ductile and one with limited ductile detailing; Zhang, $\mathrm{Lu}$ and $\mathrm{Wu}$ [6] performed quasi-static cyclic tests on six rectangular wall specimens, five with ductile and one with limited ductile detailing; Hube et al. [7] and Alarcon, Hube and Liera [8] performed quasi-static cyclic tests on nine rectangular wall specimens, two with ductile and seven with limited ductile detailing; Altheeb [9] and Albidah [10] performed quasi-static cyclic tests on two rectangular wall specimens, both with limited ductile detailing; and $\mathrm{Lu}$ [11], [12] performed quasi-static cyclic tests on eleven rectangular wall specimens, seven with ductile and four with limited ductile detailing.

None of the test specimens in these studies that were detailed with limited ductile detailing approaches (similar to that of Australian practice) had lap splices at the base of wall in the plastic hinge zone. Lowes et al. [13] tested four rectangular walls, three of which had lap splices of the vertical reinforcement at the base of the wall, however all the walls were constructed with ductile detailing. It should be noted that ductile detailing in this context is being used as a broad term to encompass any type of detailing that is deemed 'better' than typical limited ductile detailing used in Australia. No experimental studies of non-rectangular walls were identified that were similar to typical Australian construction practices mentioned earlier.

\section{EXPERIMENTAL TESTING PROGRAM}

The experimental test program consisted of two test specimens. The first test specimen, denoted S01, was a rectangular RC wall and the second test specimen, denoted S02, was a box-shaped building core specimen (Figure 1). The properties of each specimen (e.g. reinforcement ratio, shear span ratio, axial load ratio etc.) were selected to best match typical design and detailing practices used in industry, as identified by the authors in a recent reconnaissance survey [1]. The geometry of the test specimens was constrained by the test machine and as such they were designed to represent a 60 to $70 \%$ full scale ground storey wall in a real building.

Both specimens were generally detailed in accordance with the main body of AS 3600 [2], resulting in a limited ductile classification to AS 1170.4 [3]. Each specimen had a constant spaced grid of vertical and horizontal reinforcement on each face of the wall with lapped horizontal ' $U$ ' bars at the end regions of the rectangular specimen and corner interactions of the building core specimen (Figure 1). The specimens were detailed to have a moderate percentage of vertical reinforcement, as summarised in Table 1.

The walls were constructed using D500N reinforcing bars to AS/NZS 4671 [14], which have a minimum characteristic yield stress, strain hardening ratio and ultimate strain of $500 \mathrm{MPa}$, 1.08 and $5.0 \%$ respectively. The actual in-situ material properties of the reinforcement used for each test specimen is summarised in Table 2. For each entry in Table 2, a minimum of four tensile tests of rebar samples were performed.

The specimens were constructed using standard N40 grade concrete, which has a minimum characteristic 28-day compressive cylinder strength of $40 \mathrm{MPa}$. The actual concrete strength on test day varied significantly for each specimen, as shown in Table 3.

Table 1: Test specimen properties.

\begin{tabular}{lccc} 
Specimen & $\begin{array}{c}\text { Shear-span } \\
\text { ratio }\end{array}$ & $\begin{array}{c}\text { Vertical } \\
\text { reinf. ratio }\end{array}$ & $\begin{array}{c}\text { Horizontal } \\
\text { reinf. ratio }\end{array}$ \\
\hline $\mathrm{S} 01$ & 6.5 & 0.018 & 0.005 \\
$\mathrm{~S} 02$ & 6.5 & 0.014 & 0.005 \\
\hline
\end{tabular}

Table 2: Reinforcement material properties (MPa and \%).

\begin{tabular}{lcccc} 
Specimen & Reinforcement & $\mathbf{f}_{\text {sy }}$ & $\mathbf{f}_{\text {su }}$ & $\boldsymbol{\varepsilon}_{\text {su }}$ \\
\hline S01 & N20 vert. reinf. & 532.2 & 637.0 & 12.6 \\
S01 & N12 hori. reinf. & 553.1 & 705.5 & 12.7 \\
S02 & N12 vert. reinf. & 544.2 & 698.1 & 11.0 \\
S02 & N10 hori. reinf. & 544.9 & 680.1 & 12.1 \\
\hline
\end{tabular}

Table 3: Concrete cylinder strength of test specimens.

\begin{tabular}{lcc} 
Specimen & Specified strength & Actual strength \\
\hline S01 & $40 \mathrm{MPa}$ & $41.9 \mathrm{MPa}$ \\
S02 & $40 \mathrm{MPa}$ & $31.6 \mathrm{MPa}$ \\
\hline
\end{tabular}

AS 3600 does not provide any restrictions on the method or location of splicing vertical reinforcement in walls. This has resulted in a standard industry practice where the majority of walls are detailed and constructed with lap splices of the vertical reinforcement at the base of the wall, typically in the plastic hinge region. As such, the test specimens were constructed with a lap splice at the base of the wall in the plastic zone in line with this standard industry practice. The lap splice length was calculated in accordance with AS 3600 and is a function of: (i) the yield stress of the bar, (ii) the characteristic compressive strength of the concrete, (iii) the bar diameter, and (iv) the concrete cover and or bar spacing. The lap splice for specimen S01, which was detailed using N20 (i.e. $20 \mathrm{~mm} \varnothing$ ) vertical bars, was $900 \mathrm{~mm}$ and for specimen S02, which was detailed using N12 (i.e. $12 \mathrm{~mm} \emptyset$ ) vertical bars, was $500 \mathrm{~mm}$ (Figure 2). 


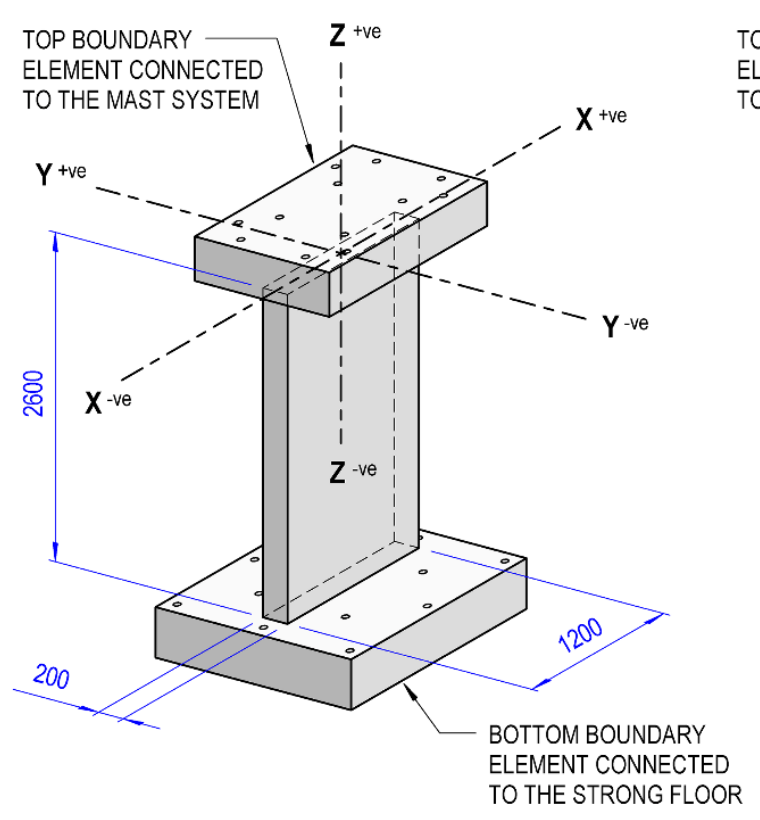

SPECIMEN S01 3D VIEW

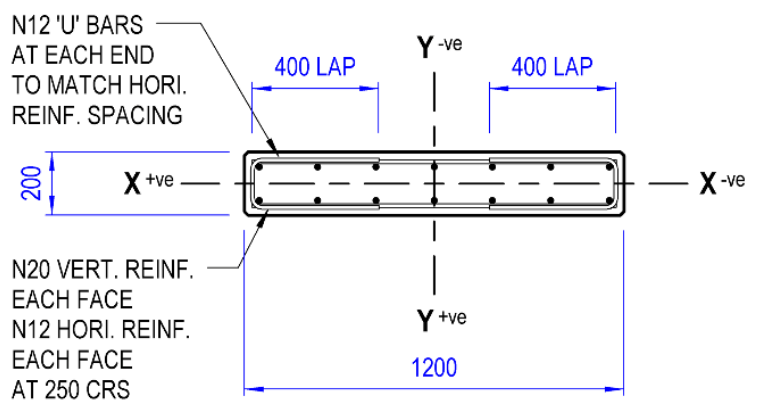

SPECIMEN S01 CROSS SECTION

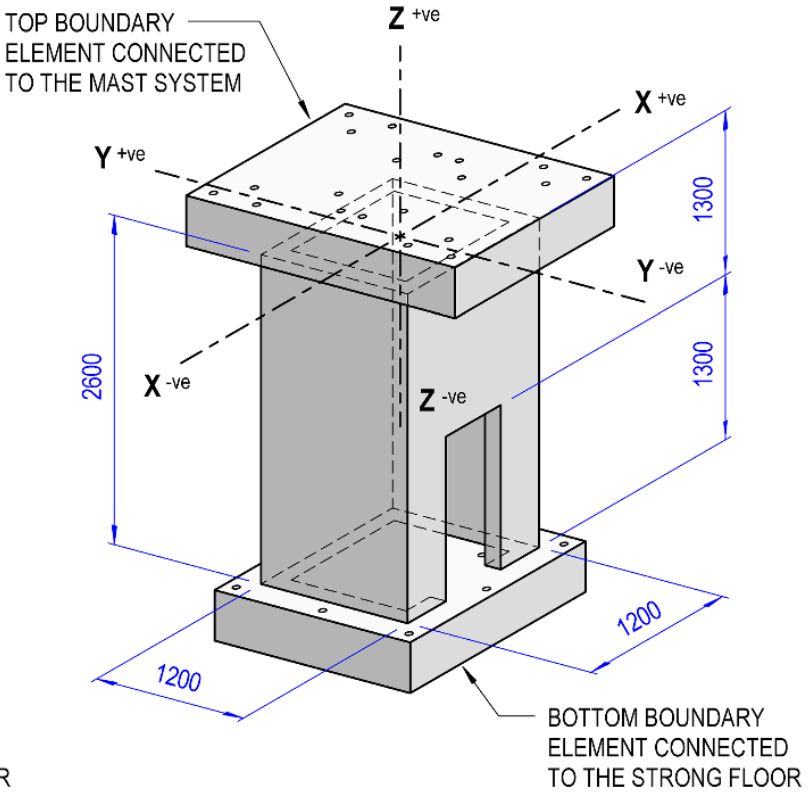

SPECIMEN S02 3D VIEW

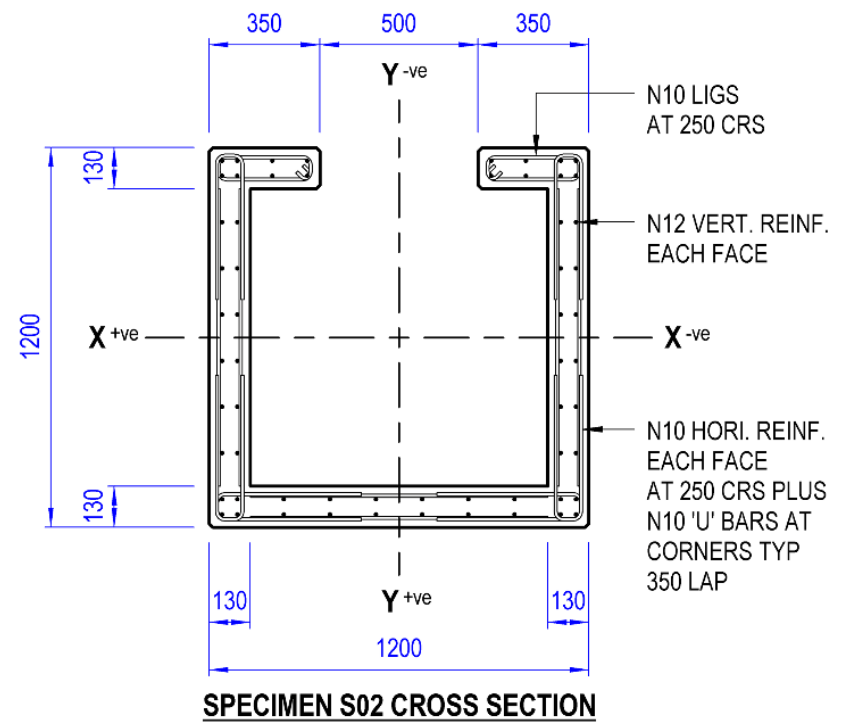

Figure 1: Test specimen geometry and reinforcement layouts.

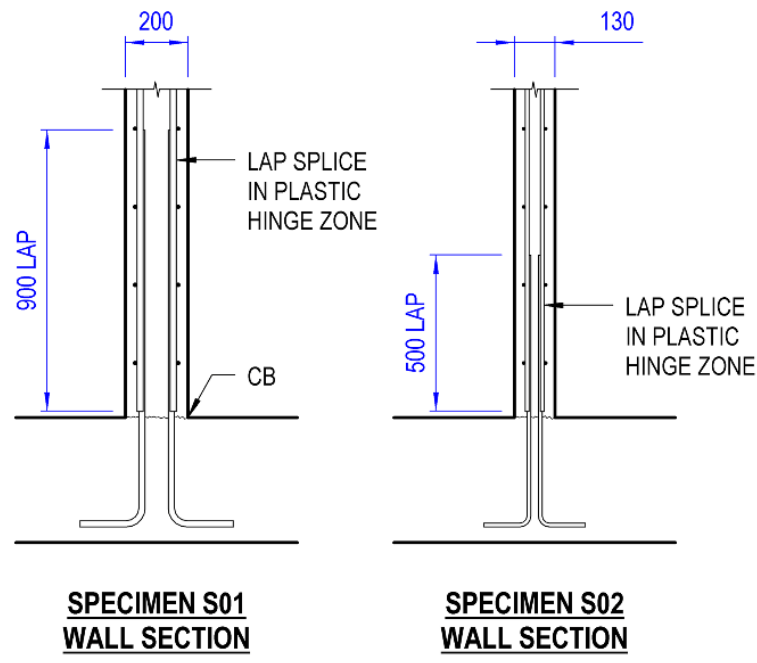

Figure 2: Lap splice detail.
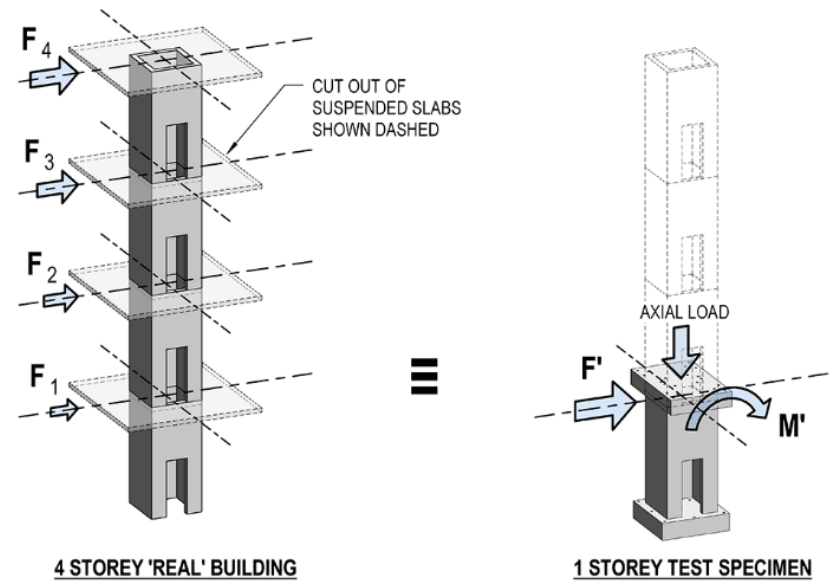

Figure 3: Simulation of four storey building response using one storey test specimen. 
The test specimens were designed to represent the ground floor component of a four storey wall and building core respectively, as shown in Figure 3. The bending moment and shear force response of the ground floor component of a taller four storey wall is simulated on the one storey test specimen using an applied lateral force and moment at the top of the specimen. To simulate this equivalent response the moment is applied as a function of the lateral force multiplied by a constant $k$. The constant $k$ is dependent on (i) the number of stories in the building, (ii) the inter-storey height of the building and (iii) the profile of the lateral load. For a four storey element with an inter-storey height of $2600 \mathrm{~mm}$ and an inverse triangular lateral load distribution the constant $k$ equals 5.2. This results in the test specimens having a shear-span ratio of 6.5. The shear span ratio is the ratio of the moment at the base of the wall to the product of the shear force and wall length, i.e. $M^{*} /\left(V^{*} L_{w}\right)$. Alternatively put, the shear span ratio is equal to the aspect ratio of the equivalent single degree of freedom system, i.e. $H_{e} / L_{w}$. The formulas for calculating the equivalent force and moment on the one storey test wall for a triangular lateral load profile are presented in Equations 1-3. The term $i$ in Equation 3 refers to the i-th floor of the wall.

$$
F^{\prime}=\sum_{i=1}^{n} F_{i}
$$

$M^{\prime}=k F^{\prime}$

$$
k=\frac{h \sum_{i=2}^{n} i(i-1)}{\sum_{i=1}^{n} i}
$$

\section{INSTRUMENTATION SETUP}

A combination of physical instrumentation attached to the test specimens, consisting of linear variable displacement transducers (LVDTs), string potentiometers and laser displacement sensors, and a contactless photogrammetry system, was used to monitor and measure the behaviour and response of the test specimens. The photogrammetry system used was the V-STARS N series by Geodetic Systems and was the primary method for quantifying the different types of deformations (e.g. flexure and shear deformation) and sectional responses (e.g. strain and curvature distributions) of the specimens. A series of string potentiometers and laser displacement sensors were used to measure the overall global displacements and rotations of the test specimen. A series of LVDTs, stacked vertically at each end of the wall, were used to verify the strain and curvature distributions determined from the photogrammetry system.

The V-STARS $\mathrm{N}$ series system is a turnkey single camera photogrammetry system, which can be used to make discrete measurements of the test specimen while the testing procedure is paused. This is in contrast to the physical instrumentation which is recording data continuously for the whole duration of testing. The system requires the user to take a series of photos of the targeted object (i.e. test specimen) from multiple points of view, which are then post processed using the V-STARS computer software to create a digital version of the targeted object's geometry. Prior to testing the specimens are covered in photogrammetry targets, as shown in Figure 4 for specimens S01 and S02, which for each set of photos taken the user will be given the $x-y-z$ movement in 3-dimensional space.

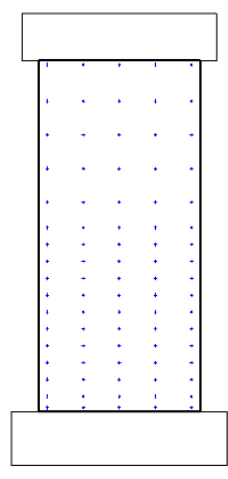

FRONT FACE

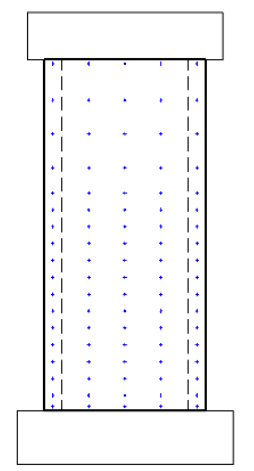

FRONT AND SIDE FACES

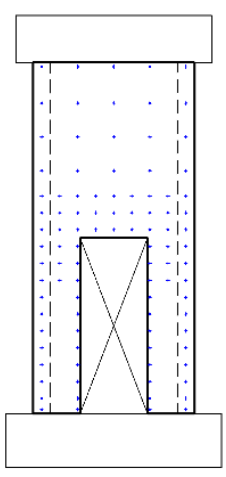

REAR FACE

\section{SPECIMEN S01}

SPECIMEN S02

Figure 4: Photogrammetry targets.

\section{TEST SETUP AND LOADING PROTOCOL}

The specimens were tested used the MAST system under a cyclic quasi-static unidirectional loading regime, as described in the following sub-sections.

\section{The MAST System}

The specimens were tested using the Multi-Axis Substructure Testing (MAST) system in the Smart Structures Laboratory (SSL) at Swinburne University of Technology. The MAST system is a state-of-the-art test machine capable of applying full six degree of freedom (DOF) loading in mixed-mode, switchedmode, hybrid or a combination therein [15]. The MAST controller uses MTS control hardware, MTS 793 Degree of Freedom software and MTS TestSuite to control the six DOFs using eight individual MTS actuators (i.e. four $\pm 1,000 \mathrm{kN}$ vertical actuators and two pairs of $\pm 500 \mathrm{kN}$ horizontal actuators in orthogonal directions). The machine can test specimens of any material or shape with a maximum plan section of $3 \times 3 \mathrm{~m}$, height of $3.35 \mathrm{~m}$ and weight of 10 tonnes. The MAST system and its associated non-concurrent DOF force capacities and displacement limits are shown in Figure 5 and Table 4 respectively.

Table 4: The MAST system non-concurrent DOF capacity.

\begin{tabular}{ccc} 
Degree of freedom & $\begin{array}{c}\text { Force } \\
\text { capacity }\end{array}$ & $\begin{array}{c}\text { Displacement } \\
\text { capacity }\end{array}$ \\
\hline $\mathrm{T}_{\mathrm{x}}-\mathrm{x}$-axis translation & $\pm 1,000 \mathrm{kN}$ & $\pm 250 \mathrm{~mm}$ \\
$\mathrm{~T}_{\mathrm{y}}-\mathrm{y}$-axis translation & $\pm 1,000 \mathrm{kN}$ & $\pm 250 \mathrm{~mm}$ \\
$\mathrm{~T}_{\mathrm{z}}$ - z-axis translation & $\pm 1,000 \mathrm{kN}$ & $\pm 250 \mathrm{~mm}$ \\
$\mathrm{R}_{\mathrm{x}}$ - -axis translation & $\pm 4,500 \mathrm{kNm}$ & $\pm 6.3^{\circ}$ \\
$\mathrm{R}_{\mathrm{y}}$ - y-axis translation & $\pm 4,500 \mathrm{kNm}$ & $\pm 6.3^{\circ}$ \\
$\mathrm{R}_{\mathrm{z}}-$ z-axis translation & $\pm 3,500 \mathrm{kNm}$ & $\pm 8.1^{\circ}$ \\
\hline
\end{tabular}

The specimens were tested under unidirectional lateral load, requiring a two-dimensional test setup. In this loading scenario, the MAST system's third dimension actuators would be performing a secondary function of stabilising the twodimensional test setup. To maximise the capacity of the MAST System the specimens are being tested at a 45-degree angle to the systems default axes. The MTS 793 Degree of Freedom software allows the user to readily move and or rotate the default axis of the system (as shown in Figure 5) as required for the test setup. 


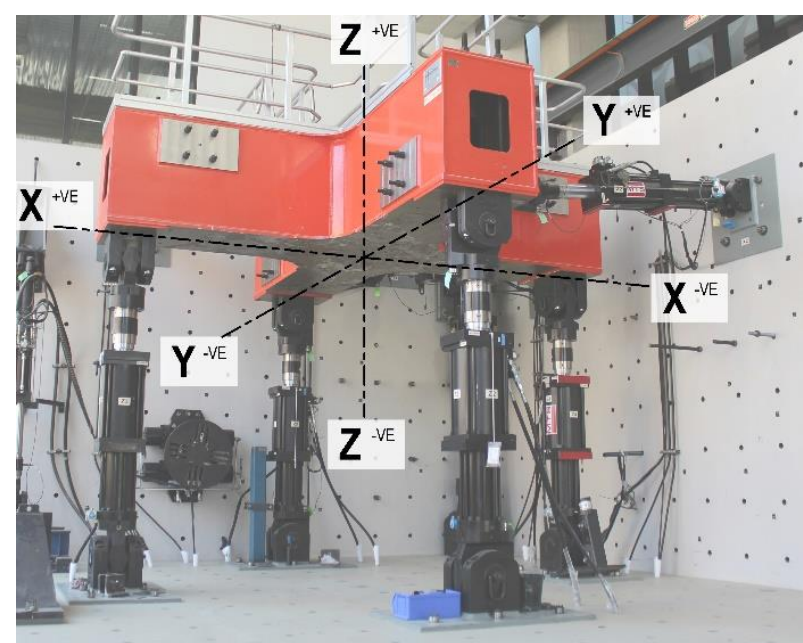

Figure 5: The MAST system at Swinburne University.

This two-dimensional test setup with the z-axis rotation of 45 degrees (as shown in Figure 6) increased the horizontal capacity of the MAST system by a factor of root 2, resulting in a horizontal capacity of $\pm 1,414 \mathrm{kN}$ with a lateral movement of $\pm 354 \mathrm{~mm}$. The moment capacity of the system also increases by a factor of root 2 to $\pm 6,364 \mathrm{kNm}$ with a rotation of $\pm 8.9^{\circ}$.

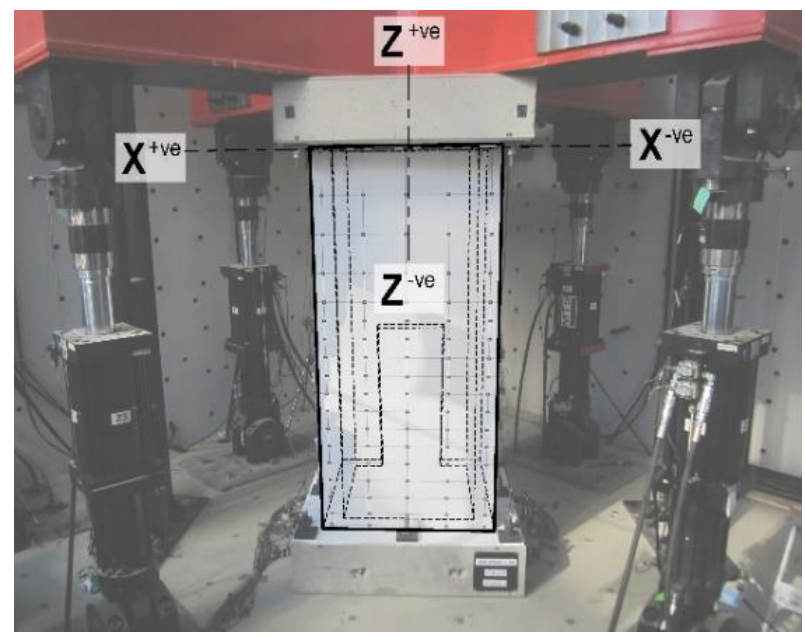

Figure 6: Test specimen in the MAST system with the 45degree axis rotation about the z-axis.

\section{Loading Protocol}

The specimens were tested under unidirectional quasi-static cyclic test conditions. Initially an axial load was applied to the test specimens to simulate the pre-compression load on the wall (i.e. the gravity load from the surrounding building). The axial load was applied in force-controlled mode in the $\mathrm{z}$-axis $\left(\mathrm{T}_{\mathrm{z}}\right)$ and maintained for the duration of the test until axial load failure of the specimen occurred (i.e. complete structural collapse). The applied axial force for specimens S01 and S02 were $-585 \mathrm{kN}$ and $-1200 \mathrm{kN}$ respectively, resulting in the axial load ratio (i.e. axial load divided by the product of the gross cross-sectional area of wall and the compressive strength of the concrete) for specimens S01 and S02 being 5.8 and $7.7 \%$ respectively. Typical axial load ratios for walls in Australia is generally between 5 and $10 \%$.

After the axial load was applied to the specimen, the specimen was subject to incrementally increasing cyclic lateral displacements in the $\mathrm{x}$-axis $\left(\mathrm{T}_{\mathrm{x}}\right)$. For each lateral displacement increment the specimens were subjected to two positive and two negative cycles, in line with the recommendations given in $\mathrm{ACI}$ 374.2R-13 [16]. After the initial series of lateral displacement cycles, the subsequent series of lateral displacement increments were determined so the next value was between $5 / 4$ and $3 / 2$ times the current displacement increment. This procedure for calculating new lateral displacement increments was determined with reference to ACI ITG-5.1-07 [17]. The test was paused at the second positive and second negative cycle of each increment to take photos, mark crack patterns and take photogrammetry measurements. The lateral $\mathrm{x}$-axis displacement loading protocols for specimens $\mathrm{S} 01$ and $\mathrm{S} 02$ are shown in Figure 7.

For the duration of the test a moment was applied about the yaxis in force-controlled behaviour to simulate the bending moment and shear force response of a taller four storey wall, with a shear-span ratio of 6.5 , in the one storey test specimen (Figure 3). The applied moment was equal to the in-plane $\mathrm{x}$-axis force multiplied by a value of 5.2 , as discussed in the previous section. The remaining out-of-plane DOFs were commanded to stay at zero displacement and rotation in displacementcontrolled behaviour for the duration of the test, i.e. $\mathrm{T}_{\mathrm{y}}$ was equal to zero movement and $R_{x}$ and $R_{z}$ was equal to zero rotation. A summary of the six DOF loading protocol is presented in Table 5.

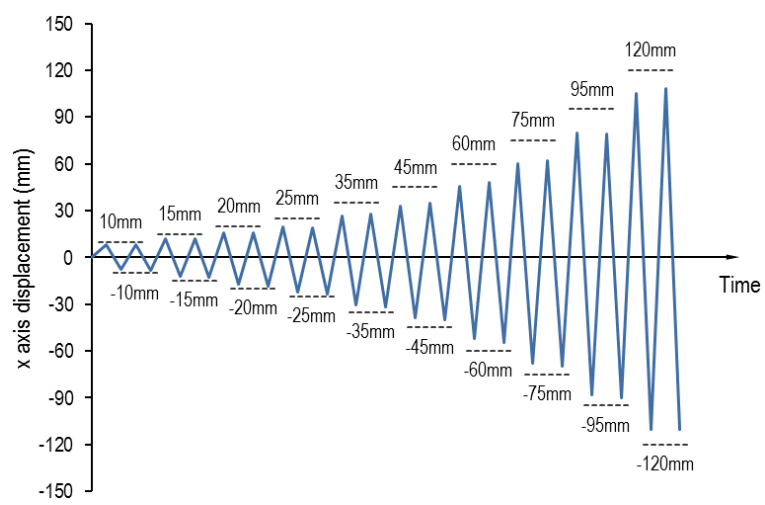

(a) Test specimen S01 - rectangular wall.

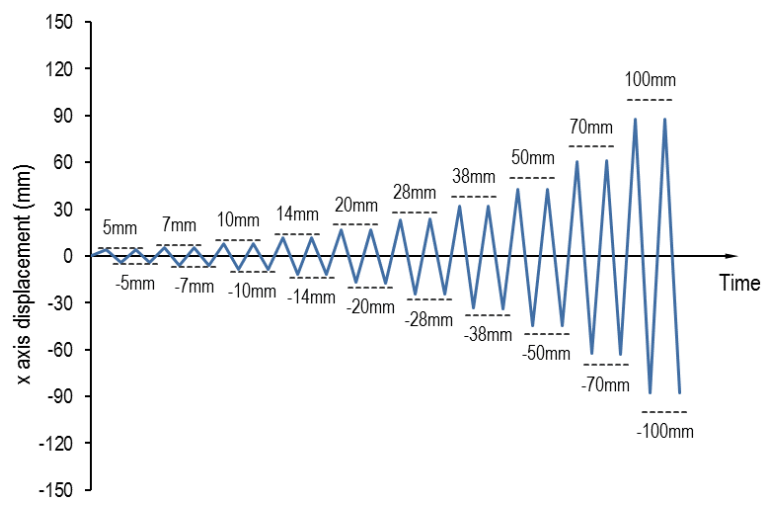

(b) Test specimen S02 - building core.

Figure 7: Cyclic $x$ direction displacement increments.

The solid line in Figure 7(a) and 7(b) denotes the actual $\mathrm{x}$-axis displacement, measured using independently mounted string potentiometers, of specimens S01 and S02 respectively. It can be seen here that the commanded $\mathrm{x}$-axis displacement values, denoted by the horizontal dashed lines in Figure 7, were not achieved. The difference between the commanded displacement and actual response of the specimen is an accumulation of (a) sliding at the interface between the bottom of the specimen and the strong floor, (b) sliding at the interface between the top of the specimen and the underside of the crosshead of the MAST system, and (c) elongation of the bolts at the top and bottom connection points of each of the eight actuators in the system. It is noted that in future tests this discrepancy could be avoided by commanding the $\mathrm{x}$-axis 
displacement values using independently mounted instrumentation.

Table 5: Loading protocol summary.

\begin{tabular}{lcc} 
Degree of freedom & Mode & Loading \\
\hline $\mathrm{T}_{\mathrm{x}}-\mathrm{x}$-axis translation & Displacement & Figure 6 \\
$\mathrm{T}_{\mathrm{y}}-\mathrm{y}$-axis translation & Displacement & Zero movement \\
$\mathrm{T}_{\mathrm{z}}-\mathrm{z}$-axis translation & Force & Constant force \\
$\mathrm{R}_{\mathrm{x}}-\mathrm{x}$-axis translation & Displacement & Zero rotation \\
$\mathrm{R}_{\mathrm{y}}-\mathrm{y}$-axis translation & Force & $M_{y}=k * F_{x}$ \\
$\mathrm{R}_{\mathrm{z}}-\mathrm{z}$-axis translation & Displacement & Zero rotation \\
\hline
\end{tabular}

\section{RESULTS}

The force-displacement and moment-rotation response of test specimens S01 and S02 are shown in Figures 9 and 12 respectively. Extreme compression strain, extreme tension strain and curvature profiles up the height of specimen S01 for positive and negative loading directions are presented in Figures 10 and 11 respectively. Likewise, for specimen S02, the same profiles for positive and negative loading directions are presented in Figures 13 and 14 respectively.

Both test specimens achieved good in-plane lateral response given the basic level of reinforcement detailed provided (e.g. no confinement reinforcement and lap splices of the vertical reinforcement at the base of the wall). Each test specimen was able to roughly achieve a displacement ductility of about 2 to 2.5 before serious strength degradation started to occur. This suggests that the force reduction factor of 2.6 given in AS 1170.4 for limited ductile RC walls is appropriate.

The displacement ductility has been discussed in general terms due to the imprecise nature of calculating ductility and the varying opinions within the research community as to what are the correct definitions of yield and ultimate displacement. For this discussion, the yield displacement was taken as a point corresponding roughly to when the initial stiffness changed significantly and the ultimate displacement as the point corresponding to lateral load failure.

The rectangular wall specimen (i.e. S01) and the building core specimen (i.e. S02) were able to undergo \pm 2.1 and $\pm 1.5 \%$
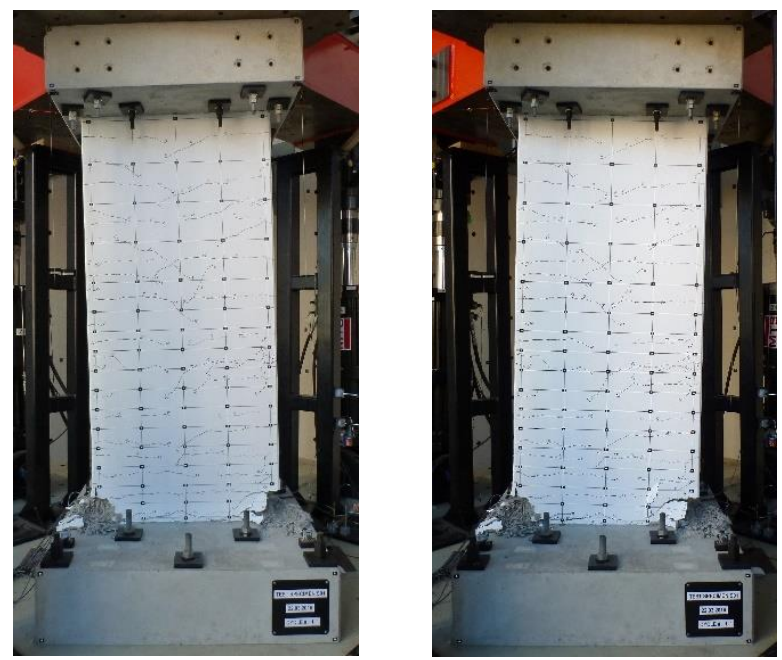

(a) S01: cycle 115 $+2.8 \%$ drift (b) S01: cycle 117 $-3.3 \%$ drift

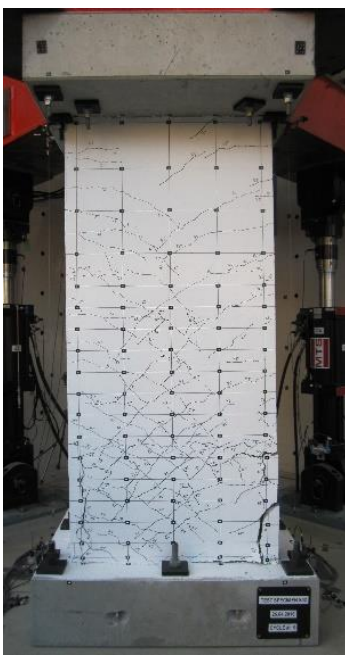

(c) S02: cycle 095 $+2.3 \%$ drift

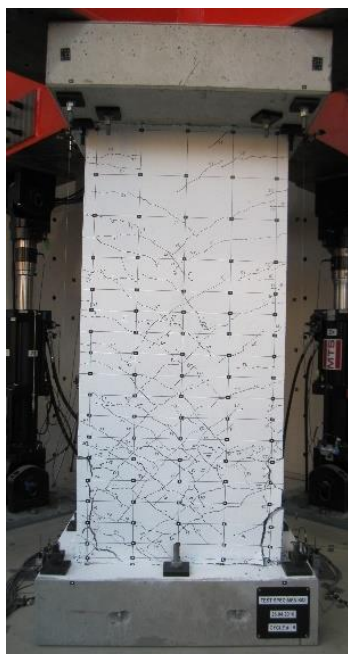

(d) S02: cycle 097 $-2.2 \%$ drift

Figure 8: Test specimen photos prior to lateral load failure (i.e. prior to strength dropping below 80 percent of the maximum). 

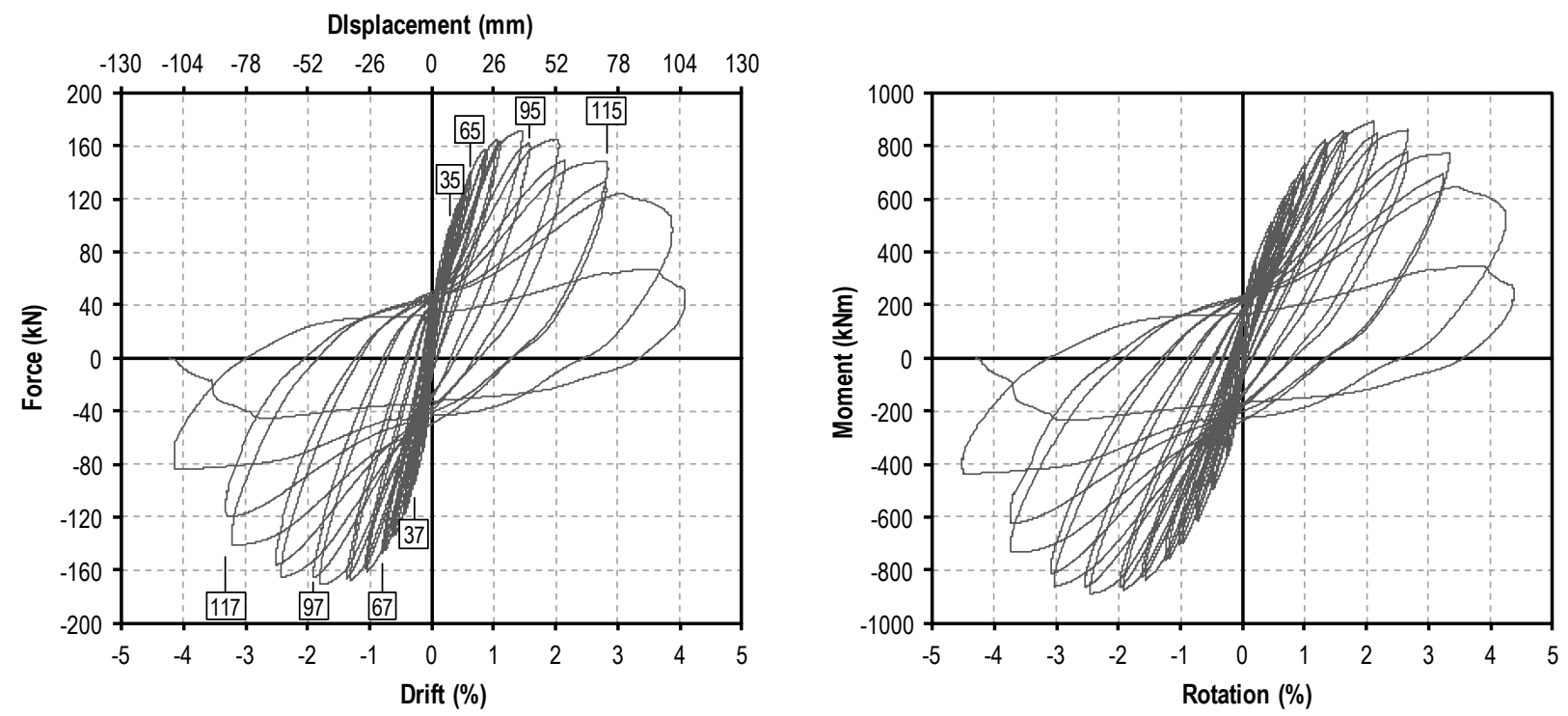

Figure 9: Specimen S01 force-displacement (left) and moment-rotation (right) response at the top of the specimen.
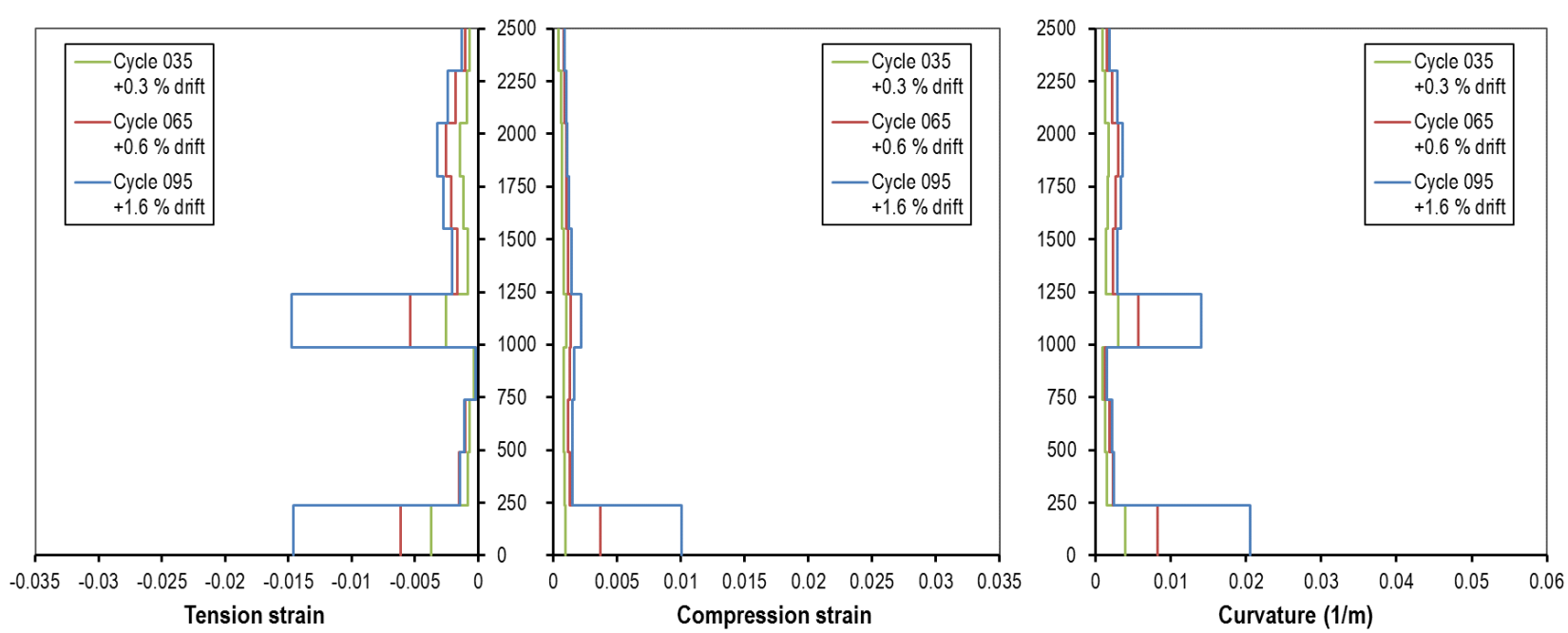

Figure 10: Specimen S01 extreme tension fibre (left) \& compression fibre (middle) strain profiles and curvature profiles (right) up the height of the specimen for the positive direction loading cycles.
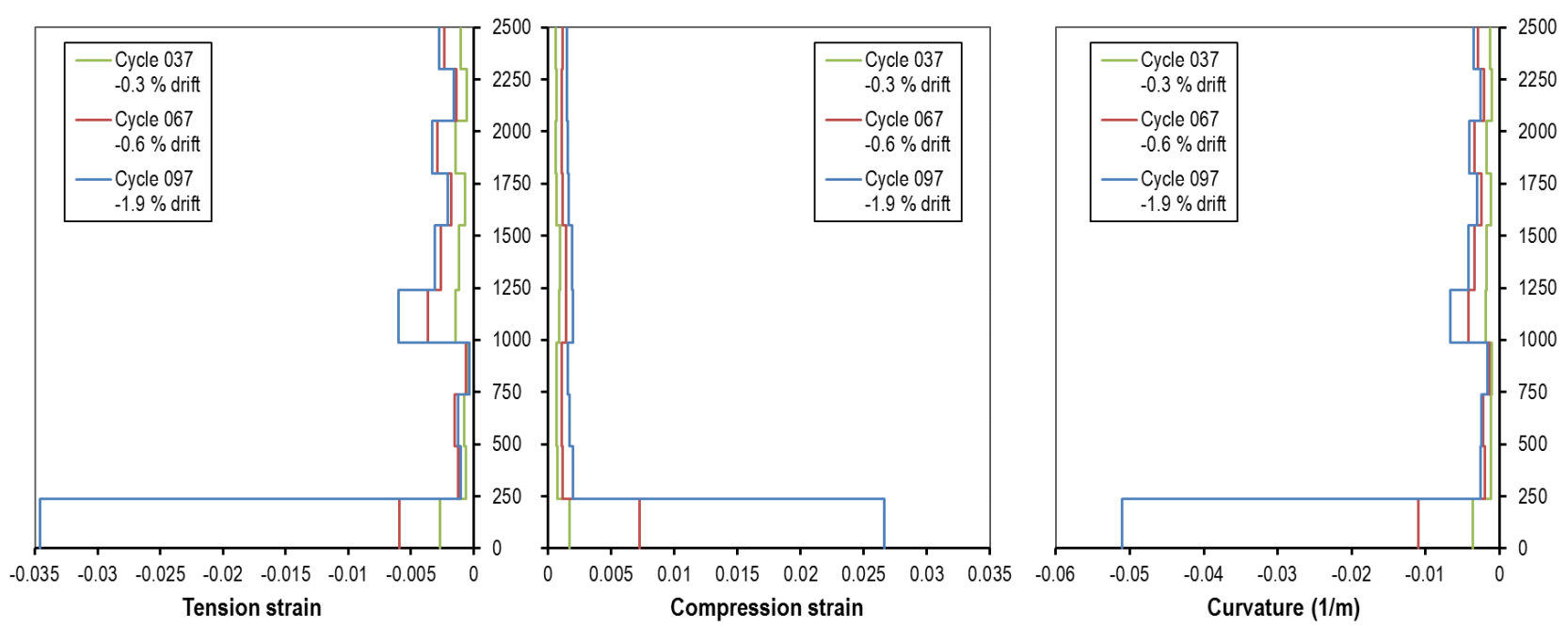

Figure 11: Specimen S01 extreme tension fibre (left) \& compression fibre (middle) strain profiles and curvature profiles (right) up the height of the specimen for the negative direction loading cycles.

Note: the cycle numbers in Figures 10 and 11 relate to the associated lateral displacement values shown on the force-displacement curve in Figure 9. Strain and curvature profiles have been determined using the photogrammetry system, i.e. V-STARS N series by Geodetic Systems. 

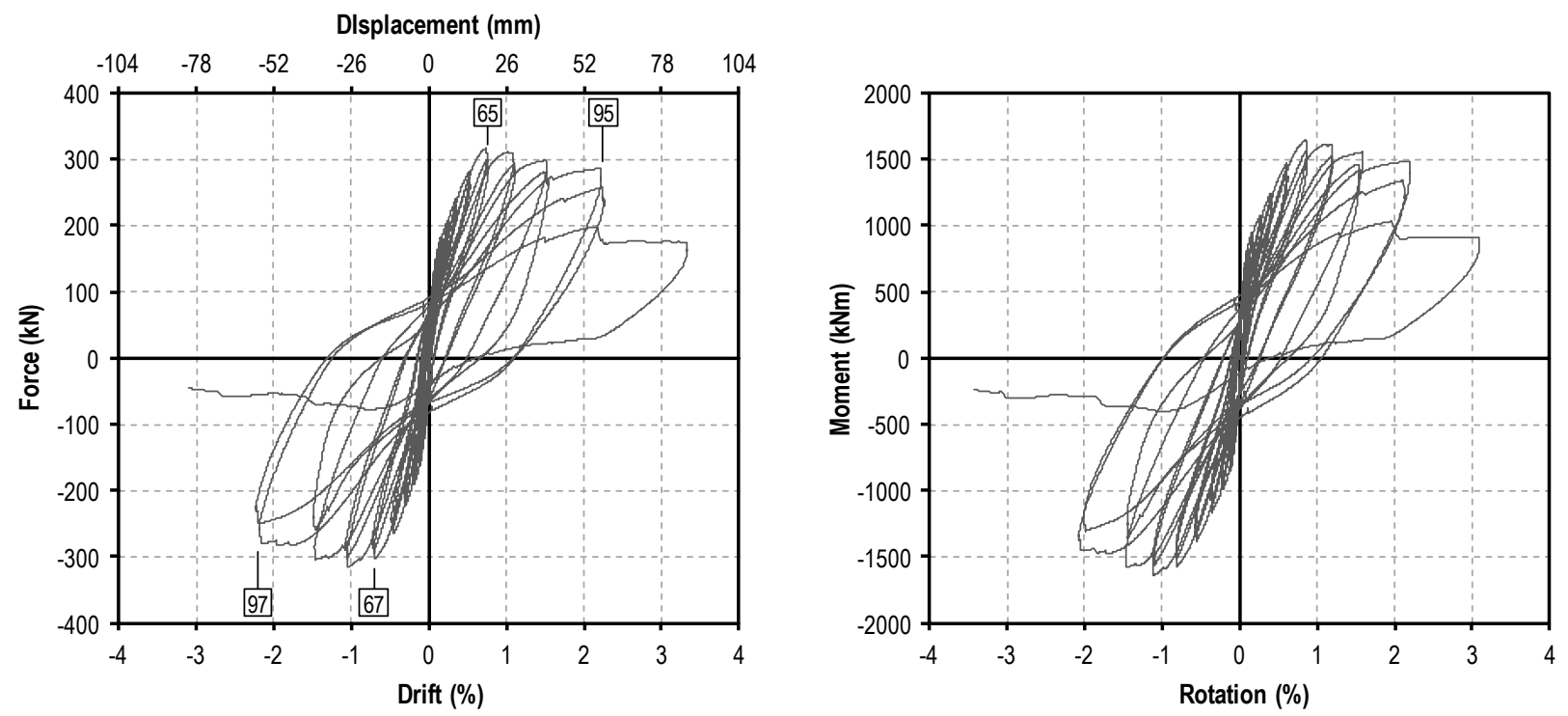

Figure 12: Specimen S02 force-displacement (left) and moment-rotation (right) response at the top of the specimen.
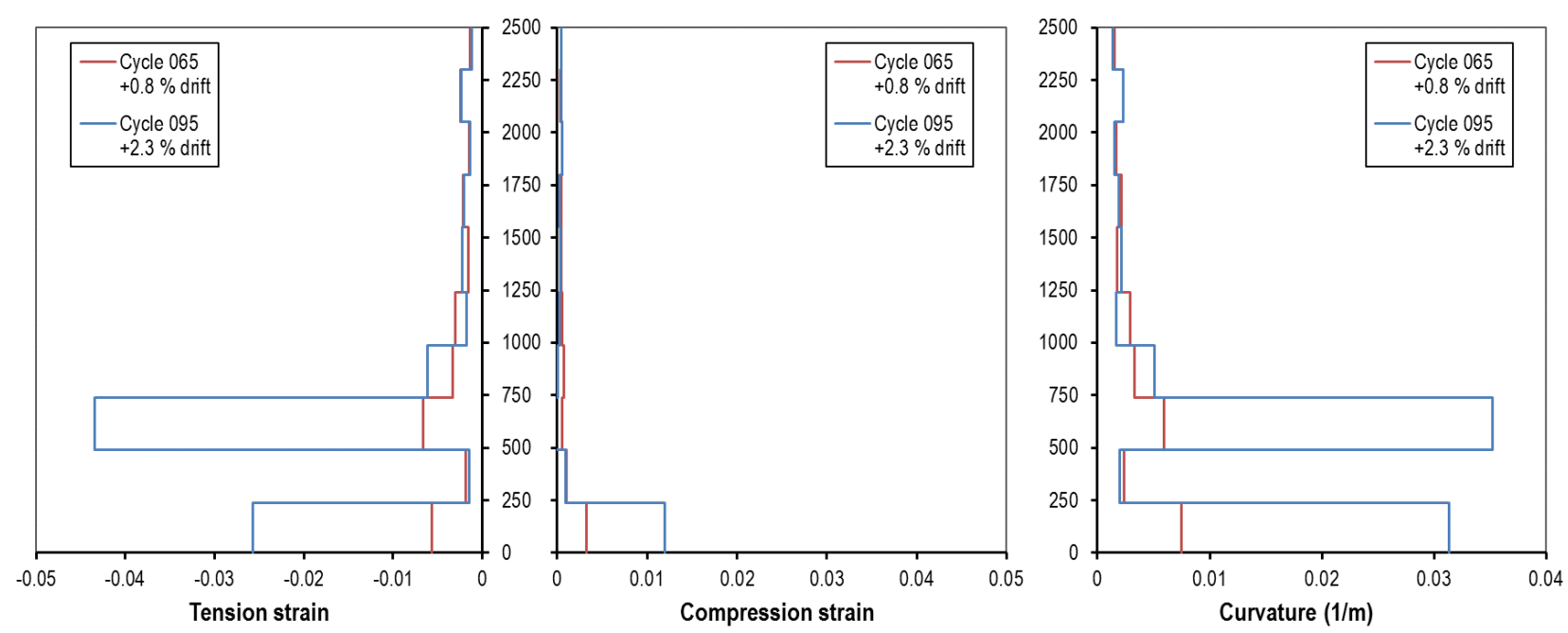

Figure 13: Specimen S02 extreme tension fibre (left) \& compression fibre (middle) strain profiles and curvature profiles (right) up the height of the specimen for the positive direction loading cycles.
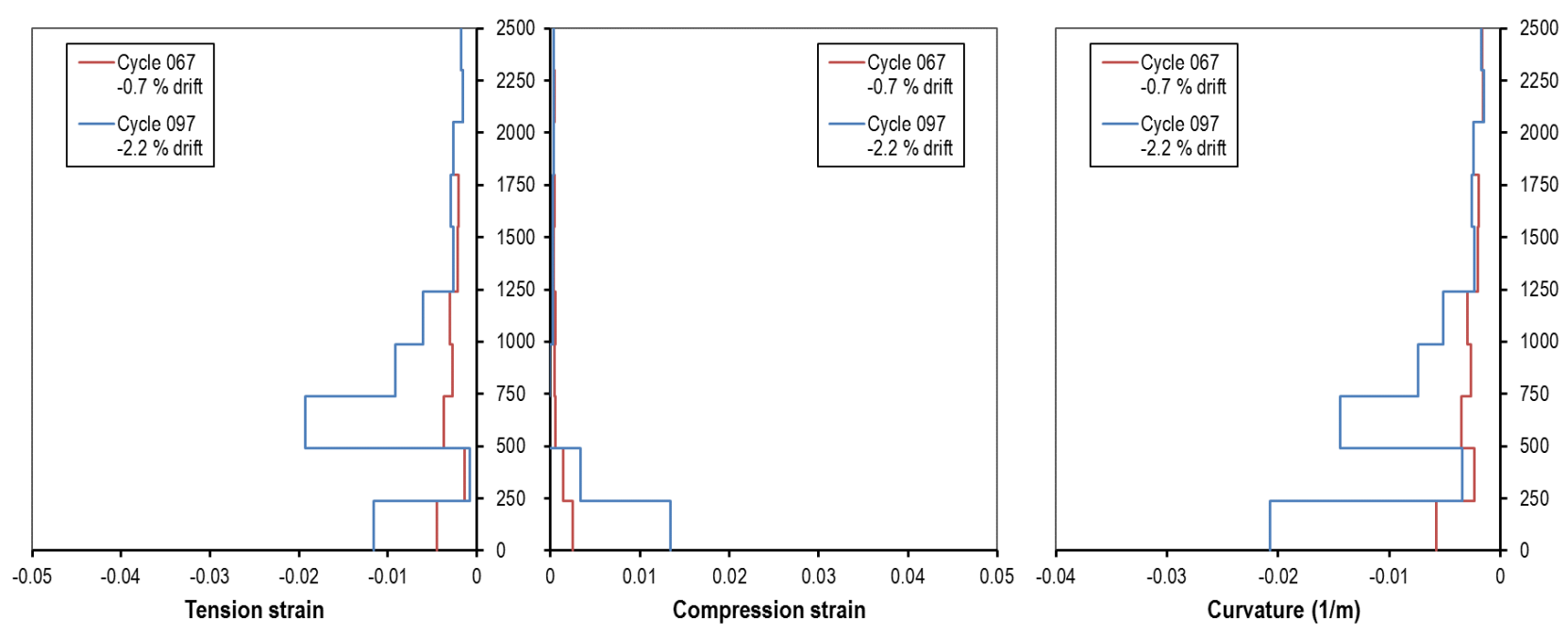

Figure 14: Specimen S02 extreme tension fibre (left) \& compression fibre (middle) strain profiles and curvature profiles (right) up the height of the specimen for the negative direction loading cycles.

Note: the cycle numbers in Figures 13 and 14 relate to the associated lateral displacement values shown on the force-displacement curve in Figure 12. Strain and curvature profiles have been determined using the photogrammetry system, i.e. V-STARS N series by Geodetic Systems. 
Prior to lateral load failure of specimen S02, the building core underwent a minor loss in its lateral strength equal to approximately $10 \%$ of its maximum capacity, occurring from a lateral drift value of $0.8 \%$ up to a value of $2.2 \%$ (refer Figure 12). This loss in lateral strength prior to lateral load failure is believed to be the result of a different mechanism than that discussed in the previous paragraph. After the moulds were stripped during construction of the building core it was seen that some areas towards the base of wall needed to be patch fixed because poor vibration of the concrete was achieved in these locations. The gradual $10 \%$ loss in lateral capacity prior to the 'real' lateral load failure is believed to be due to local failure of these patch repaired sections of concrete near the base of the wall.

The rectangular wall specimen achieved lower levels of drift to three walls tested by Lu et al. [12], which all had non-ductile detailing. These three walls all achieved a lateral drift of $2.6 \%$ before significant lateral strength degradation started to occur, which is better than the performance observed in this test. The rectangular wall specimen had a higher drift capacity than the non-ductile wall specimen by Dazio et al. [5], however it had much less lateral strength degradation and had a much smaller shear span ratio (2.3 versus 6.5$)$.

\section{PLASTIC HINGE DEVELOPMENT}

The post yield deformation response was somewhat different to the response commonly seen in $\mathrm{RC}$ wall testing performed generally in literature. Typically - when no lap splice is present at the base of the wall - the wall either develops a traditional plastic hinge with distributed cracking at the base of the wall, where the inelastic plastic behaviour is 'spread' across multiple cracks, or when the percentage of vertical reinforcement is not sufficient to initiate distributing cracking, a single crack forms with a concentration of the inelastic plastic behaviour in one location (i.e. Figure 15(a) and 15(b) respectively). The latter of these two scenarios, which has received much research attention in recent years (e.g. [12, 18, 19]), has a significantly reduced inelastic displacement capacity compared to the former and is generally associated with the scenario where the cracking moment capacity of the wall is greater than the ultimate moment capacity of the wall.

It has been shown in this testing that neither of the two aforementioned post-yield plastic hinge models are developed. The lap splice at the base of the wall - which is common practice in Australia and generally associated with limited ductile RC wall detailing - results in a region at the base of the

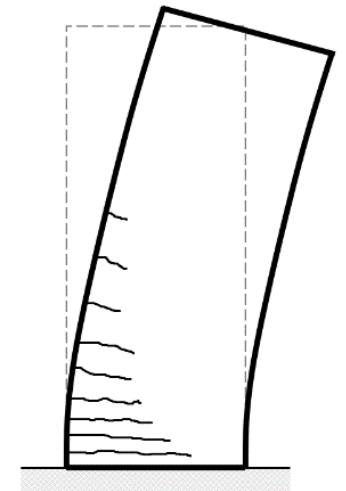

(a) traditional plastic hinge model with distributed cracking.

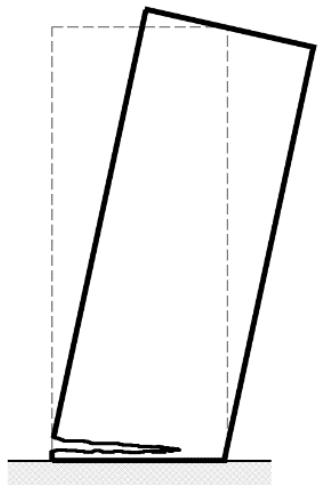

(b) single crack plastic hinge model (under-reinforced section).

wall having effectively double the amount of vertical reinforcement and hence a much larger moment capacity than the section of wall directly above and below the lap splice. This results in a region of overstrength at the base of the wall where only hairline cracks develop. This behaviour leads to the development of either a 'two-crack' plastic hinge model or a single crack plus a shifted traditional hinge plastic hinge model (i.e. type c Figure 15(c) and type d Figure 15(d) respectively).

The two-crack plastic model is where only two predominated cracks develop, one at the bottom of the lap splice and one at the top of the lap splice, with the majority of the plastic behaviour concentrated in these two locations. The shifted plastic hinge model is where a traditional plastic hinge (i.e. Figure 15(a)) develops at the top of the lap splice, in addition to a single large crack forming at the base of the splice. The former and latter responses will be dictated by the ratio of the applied moment at the base of the wall to the applied moment at the top of the lap splice, which is in turn dependent on the shear-span ratio of the wall (i.e. slenderness).

A similar type of behaviour was observed in an experimental study by Lowes et al. [13], which included three ductile rectangular wall specimens with lap splices of the vertical reinforcement in the plastic hinge zone. It was reported that the lap splice resulted in the damage being concentrated at the top and bottom of splice, similar to what was observed in this testing.

The curvature distributions of the rectangular wall specimen (i.e. S01) in Figures 10 and 11 show the two-crack plastic hinge model was formed in the wall (i.e. type c Figure 15(c)). Interestingly, the two-crack plastic hinge is more prominently seen in the positive loading direction with close to equal amounts of curvature at the base of the wall and the top of the splice respectively. Whereas, in the negative loading direction, the majority of the curvature is concentrated at the base of the wall with another little spike of curvature at the top of the splice.

The curvature distributions of the building core specimen (i.e. S02) in Figures 13 and 14 show the two-crack plastic model was formed in the wall, however in the positive loading direction the type c model was developed and in the negative loading direction the type $\mathrm{d}$ model was developed. It is interesting to note that for both specimens the amount of flexure deformation contributing to the total deformation in the positive and negative loading was different, i.e. the sum of the curvature distribution in the positive direction of loading does not equal the sum of the curvature in the negative direction.

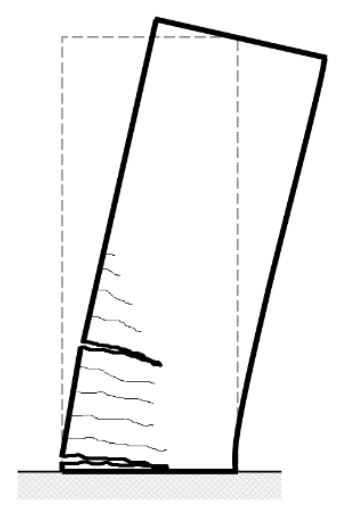

(c) two-crack plastic hinge model (lap splice at base of the wall).

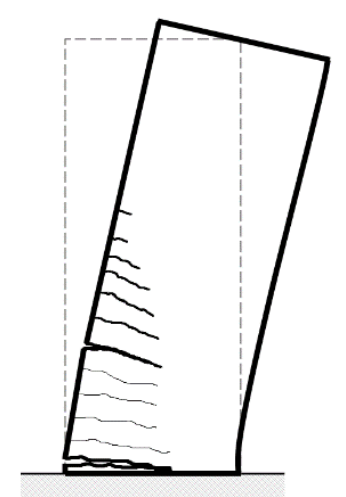

(d) shifted plastic hinge model (lap splice at base of the wall).

Figure 15: Plastic hinge development in RC walls. 


\section{CONCLUSIONS}

This paper has presented the details and results of a recent experimental testing program into $\mathrm{RC}$ walls detailed and constructed to conform and best match standard industry practices in Australia. The experimental program consisted of one $\mathrm{RC}$ wall specimen with a rectangular cross-section and one RC box shaped building core specimen. The specimens both achieved a displacement ductility of about 2 to 2.5 before serious strength degradation started to occur, which is in good agreement with the ductility assumptions usually adopted by Australian designers when using the Australian earthquake loading standard, AS 1170.4. The ultimate failure mechanism of the rectangular wall was crushing of the concrete in the extreme compressive fibre of the wall, whereas the building core specimen failed due to the development of high tensile strains in the vertical reinforcement, which resulted in a combination of fracturing of the vertical reinforcement, unzipping of the lap splice and degradation of the concrete due to bond failure between the concrete and reinforcement.

The rectangular wall and building core specimens were able to achieve \pm 2.1 and $\pm 1.5 \%$ lateral drift respectively prior to lateral load failure of the specimens occurring (i.e. the lateral strength dropped below $80 \%$ of the respective maximum capacity). The walls continued to achieve \pm 4.4 and $\pm 4.6 \%$ lateral drift respectively prior to axial load failure occurring (i.e. complete structural collapse). The test results of both specimens showed that a traditional plastic hinge with distributed cracking and distributed plasticity, as commonly seen in RC wall testing, was not achieved due to the lap splice at the base of the wall. The lap splice created a region of overstrength, over which only hairline cracks formed with major cracks either side, i.e. at the base of the wall and the top of the lap splice. The plastic rotation and curvature of the wall was concentrated within these two locations.

\section{ACKNOWLEDGEMENTS}

The authors would like to thank the Brown family for their generous donation in establishing the Dr William Piper Brown AM Scholarship, of which the lead author is the recipient. Financial support from the Australian Research Council (ARC) Discovery Project DP140103350 entitled Collapse Assessment of Reinforced Concrete Buildings in Regions of Lower Seismicity is gratefully acknowledged. The Swinburne Smart Structures Laboratory staff are also thanked for their hard work and expertise provided during the course of the experimental testing program.

\section{REFERENCES}

1 Menegon SJ, Wilson JL, Lam NTK and Gad EF (2017). "RC Walls in Australia: Reconnaissance Survery of Industry and Literature Review of Experimental Testing". Australian Journal of Structural Engineering, 18(1): 24-40.

2 Standards Australia (2009). "AS 3600-2009 Concrete Structures". SAI Global Limited, Sydney, Australia.

3 Standards Australia (2007). "AS 1170.4-2007 Structural Design Actions, Part 4: Earthquake Actions in Australia". Standards Australia, Sydney.

4 Lestuzzi P and Bachmann H (2007). "Displacement ductility and energy assessment from shaking table tests on RC structural walls". Engineering Structures, 29(8): 17081721.
5 Dazio A, Beyer K and Bachmann H (2009). "Quasi-static cyclic tests and plastic hinge analysis of RC structural walls". Engineering Structures, 31(7): 1556-1571.

6 Zhang H, Lu X and Wu X (2009). "Cyclic Loading Experiment and Numerical Simulation of RC Walls". Proceedings of the 2009 World Congress on Computer Sciences and Information Engineering, Los Angeles, USA.

7 Hube MA, Marihuen A, Liera JCDL and Stojadinovic B (2014). "Seismic behaviour of slender reinforced concrete walls". Engineering Structures, 80: 377-388.

8 Alarcon C, Hube MA and Liera JCDL (2014). "Effect of axial loads in the seismic behaviour of reinforced concrete walls with unconfined wall boundaries". Engineering Structures, 73: 13-23.

9 Altheeb A (2016). "Seismic Drift Capacity of Lightly Reinforced Concrete Shear Walls". PhD thesis, Department of Infrastructure Engineering, Univeristiy of Melbourne, Melbourne, Australia.

10 Albidah A (2016). "Vulnerability and Risks of Collapse of Structural Concrete Walls in Regions of Low to Moderate Seismicity". PhD thesis, Department of Infrastructure Engineering, University of Melbourne, Melbourne, Australia.

11 Lu Y (2017). "Seismic Design of Lightly Reinforced Concrete Walls". PhD Thesis, Department of Civil and Environmental Engineering, The University of Auckland, Auckland, New Zealand.

12 Lu Y, Henry RS, Gultom R and Ma QT (2017). "Cyclic Testing of Reinforced Concrete Walls with Distributed Minimum Vertical Reinforcement". Journal of Structural Engineering, 143(5), DOI:10.1061/(ASCE)ST.1943541X.0001723.

13 Lowes LN, Lehman DE, Birely AC, Kuchma DA, Marley KP and Hart CR (2012). "Earthquake response of slender planar concrete walls with modern detailing". Engineering Structures, 43: 31-47.

14 Standards Australia and Standards New Zealand (2001). "AS/NZS 4671:2001 Steel Reinforcing Materials". Standards Australia International Ltd, Sydney and Standards New Zealand, Wellington.

15 Hashemi MJ, Al-Mahaidi R, Kalfat R and Burnett G (2015). "Development and validation of multi-axis substructure testing system for full-scale experiments". Australian Journal of Structural Engineering, 16(4): 302315.

16 American Concrete Institute (2013). "ACI 374.2R-13 Guide for Testing Reinforced Concrete Structural Elements under Slowly Applied Simulated Seismic Loads". American Concrete Institute, Farmington Hills, Michigan, USA.

17 American Concrete Institute (2008). "ACI ITG-5.1-07, Acceptance Criteria for Special Unbonded Post-Tensioned Precast Structural Walls Based on Validation Testing and Commentary". American Concrete Institute, Farmington Hills, Michigan, USA.

$18 \mathrm{Lu} \mathrm{Y}$ and Henry RS (2017). "Numerical modelling of reinforced concrete walls with minimum vertical reinforcement". Engineering Structures, 143: 330-345.

19 Hoult R, Goldsworthy H and Lumantarna E (2017). "Plastic Hinge Length for Lightly Reinforced Rectangular Concrete Walls". Journal of Earthquake Engineering, DOI:10.1080/13632469.2017.1286619 (In Press). 